\title{
The presence of injunctions in clinical and non-clinical populations
}

\author{
(C) 2012 Danijela Budiša, Vesna Gavrilov-Jerković, Aleksandra Dickov, \\ Nikola Vučković, Sladjana Martinovic Mitrovic
}

\begin{abstract}
Various authors within the transactional analysis community have postulated that a person's life script is formed on the basis of received injunctions, that people with mental disorders have more destructive and numerous injunctions and that people with depressive and paranoid pathology have different sets of injunctions, with Don't belong being more common in paranoid disorders and Don't be important in depressive disorders. This research was conducted to check such assertions, and used Script Injunctions Scale (GavrilovJerković et al., 2010) applied to a convenience sample of 100 adult subjects identified as non-clinical via interviews and 100 adult subjects, equally divided between paranoid and depressive, identified by psychiatrist classification based on ICD-10 criteria. The results provide partially expected validation, with statistically significant difference between the nonclinical and clinical part of the sample. The clinical group had statistically significantly higher scores on the 12 injunctions studied. Subjects with depressive characteristics had seven Injunctions which were more pronounced Don't feel, Don't exist, Don't be well, Don't be a child, Don't, Don't think, and Don't be close Injunctions.
\end{abstract}

Key words

Transactional Analysis, Injunctions, Depressive, Paranoid

\section{Introduction}

\section{Definitions}

Berne (1972) defined injunctions as repeated and traumatic early parental messages that lead to chronic dysfunction in vital areas of life. It is considered that injunctions limit one's freedom, i.e. they discourage a child's development and make life more difficult (Lammers 1994). Berne postulated that injunctions act automatically, like an 'electrode', independent from the will of other parts of child's personality (p. 115-117).
Injunctions are also defined as negatively formulated messages that limit autonomy. It is assumed that they are often non-verbal and transmitted at the psychological level of communication (Stewart and Joines, 1996). Goulding \& Goulding (1979) ascribed injunctions to parental influence, as well as to child activity. They considered that the child's script would be determined by the parental messages that the child has recognised and accepted as important. They also assumed that there are some messages the parent never conveys to the child, but which the child alone has directed to themself. Therefore, according to their theoretical stance, the script and early decisions are auto-determined, rather than hetero-determined as suggested by Berne. In their view, the reason why parents communicate injunctions most likely lies in their feelings of inadequacy, confusion, discontent, anxiety, unhappiness, disappointment, anger, frustration, and secret desires. Injunctions originate from the parent's Child ego state.

\section{Lists of injunctions}

Goulding \& Goulding (1976) defined the first list of injunctions and later made several additions to it (Goulding and Goulding, 1978). One of the variations of the list comprises the following injunctions: Don't exist, Don't be important, Don't be you, Don't be a child, Don't grow up, Don't succeed, Don't be close, Don't belong, Don't think (either about a forbidden topic or differently from your parents), Don't feel (a forbidden feeling or different from parents), Don't be well (or Don't be sane), and Don't (prohibition of various activities conveyed by a hyper-protective mother).

McNeel (1976) extended considerably the Goulding \& Goulding list whereas Hartman \& Narboe (1974) believed that there are only two fundamental injunctions: Don't exist and Don't be sane. Other injunctions, such as Don't belong and Don't succeed, provide an exit that does not imply death or insanity. 
Links to mental disorders

According to transactional analysis theory, it is assumed that a person's life script is formed on the basis of received injunctions. Furthermore, it is believed that people with mental disorders have more destructive and numerous injunctions, and that people with depressive and paranoid pathology have different sets of injunctions. According to several authors (Ernst, 1971, Berne, 1972, Steiner, 1974, Goulding \& Goulding, 1979, Erskine \& Zalcman, 1979, Joines \& Stewart, 2002), typical injunctions for those with paranoid disorders include: don't be a child, don't be close, don't feel (fear, sadness, guilt), don't belong, whilst those with depressive disorders might have permissions to exist and to be important but countered by injunctions: don't be you, don't grow up, don't think, don't feel (angry), don't be a child.

Several authors have undertaken research into injunctions and different Script Questionnaires have been used clinically for years, including Berne (1972), Steiner (1967) and Holloway (1973). Drego (1994) made a scale called the 'Drego Injunction Scale' and Björk (1997) published a study showing that the scale was not valid when it came to different injunctions, but had a certain validity in measuring hamartic life script.

Italian author Scilligo et al (1999) constructed the ESPERO scale to test injunctions according to Goulding \& Goulding's classification and drivers according to Kahler's (1975) definition. Scilligo's research confirmed that injunctions are a theoretical concept that can be tested using a questionnaire. Johnsson (2011) published a study in which he showed that the interassessor reliability in script diagnosis on an overall basis was moderate and low on a specific level.

\section{Objectives of Research}

Clearly, these concepts have both theoretical and practical implications for the understanding of diagnostic and therapeutic work with people with different psychopathological manifestations, including depressive and paranoid symptoms. However, it should be noted that these postulates still do not have sufficient empirical support within the TA theoretical framework. This empirical deficiency can be found not only in the concept of injunctions, but also, unfortunately, in much of TA theory, in the sense that there have been few studies on TA constructs in different psychopathological categories and nonclinical populations.

Operationalisation of this theoretical construct can enable assessment of the psychotherapeutic work on injunctions, and better and more valid clinical evaluation of the client's initial condition, especially if the norms have been formed on the nonclinical population. Furthermore, evaluation of the concept of injunctions on different clinical populations may indirectly contribute to the assessment of relative expression of other psychopathological tendencies. For example, if a person has the Don't belong injunction, we can assume that his cognitive schemes, behavioural and emotional characteristics will be maladaptive following the paranoid type. Confirmation of the possibility of assessing the concept of injunctions can therefore enable more effective therapeutic work that would be directed at the basic problems in the client's psychological functioning.

From the above-mentioned theoretical implications and the implied significance of examining theoretical concepts in TA, especially in the context of relations between clinical and nonclinical populations, arose the objectives of our study:

1. testing the potential of the theoretical concept of injunctions to differentiate nonclinical and clinical populations;

2. among clinical populations, to differentiate paranoid from depressive subjects;

3. to determine the structure of injunctions specific for these two clinical populations.

\section{Methods}

The design of the research was non-experimental (correlational). Script injunction is the dependent variable, operationalised through subjects' answers to Script Injunctions Scale (Gavrilov-Jerković et al., 2010).

The non-clinical sample of 100 subjects was collected in several companies in Novi Sad and vicinity, following the principle of convenience sample. The only eliminatory criterion within the non-clinical sample was if they ever received psychiatric treatment, which was determined in an interview. The fulfilment of the diagnostic criteria for the spectrum of depressive and paranoid disorders was assessed by treating psychiatrists, who classified the subjects according to a diagnostic interview and the ICD-10 diagnostic criteria (WHO, 1992).

Control variables were depression as a personality trait and tendency to paranoid ideation and hypersensitivity, as assessed by the questionnaires. These were included in the study as a means to control the presence of depressive and paranoid characteristics in the nonclinical group as well as to control the validity of the psychiatric diagnosis in the clinical group. A number of demographic variables, such as sex, age, marital status, education, employment, which could be helpful in the interpretation of results obtained on the dependent variable, were also recorded. It should be emphasized that differences in the variables education and employment between the clinical and nonclinical group were expected, considering professional deterioration of the clinical population. 
Table 1: Examples of items (translated) comprisng 12 subscales

\begin{tabular}{|c|c|c|}
\hline Injunction & No. of items & Examples \\
\hline Don't Be! & 10 & $\begin{array}{l}\text { I have an impression that everything is my fault; I am a nuisance to } \\
\text { everyone. }\end{array}$ \\
\hline Don't be You! & 3 & $\begin{array}{l}\text { Persons of the opposite sex have it much easier throughout life; My parents } \\
\text { wanted a child of the opposite sex than I am. }\end{array}$ \\
\hline Don't be a child! & 2 & I was often not allowed to play; I can't find fun in anything. \\
\hline Don’t Grow up! & 6 & $\begin{array}{l}\text { I decidedly dislike responsibility; i would like to always remain a child, in that } \\
\text { way I would have less problems in life. }\end{array}$ \\
\hline Don't Succeed! & 6 & $\begin{array}{l}\text { I almost never do something properly; I was criticized that I never do things } \\
\text { well enough. }\end{array}$ \\
\hline Don’t! & 6 & $\begin{array}{l}\text { I have a hard time making a decision; I worry more than other people if I shall } \\
\text { make a mistake when I have to do something. }\end{array}$ \\
\hline Don't be Important! & 6 & $\begin{array}{l}\text { I am not as worthy as other people; I have an impression I was not important } \\
\text { to my parents }\end{array}$ \\
\hline Don’t Belong! & 8 & $\begin{array}{l}\text { I have an impression that I don't belong to my family; I don't have much in } \\
\text { common with my family. }\end{array}$ \\
\hline Don't be Close! & 5 & I was rarely fondled as a child; I have difficulties befriending people. \\
\hline Don't be Well! & 3 & $\begin{array}{l}\text { Parents paid attention to me only when I was sick; They were telling me that I } \\
\text { am crazy when I was a child. }\end{array}$ \\
\hline Don't Think! & 8 & $\begin{array}{l}\text { I think I am slower to understand than other people; I find it difficult to } \\
\text { concentrate. }\end{array}$ \\
\hline Don’t Feel! & 8 & $\begin{array}{l}\text { I very often have a problem to determine what I really feel; As a child, I was } \\
\text { not allowed to express what I really felt. }\end{array}$ \\
\hline
\end{tabular}

Research instruments used in the study:

Script Injunction Scale (Gavrilov-Jerković et al., 2010) was used to evaluate script injunctions. This scale measures the degree and type of the 12 script injunctions that a person was exposed to during childhood and has accepted as a part of self image. It contains 71 items formulated as statements to which subjects specify their level of agreement on a five-point Likert scale. The reliability of the whole scale expressed as Cronbach alpha coefficient is 0.96 and of the subscales is between 0.48 and 0.83 . The Scale has good concurrent and discriminant validity. Examples of certain items (translated) within the subscales are given in the Table 1, as well as the number of items comprising each subscale.

LD Scale, Scale of depressive personality (Novović et al., 2007), is comprised of 26 items and is based on Schneider's (1958) description of depressive personality, that Akiskal (1997) has formalised into seven traits:

1. calm, introverted, passive and non-assertive

2. dreary, pessimistic, serious and incapable of humour

3. self-critical, self-accusing and self-demeaning
4. sceptical, hyper-critical and hard to please

5. scrupulous, responsible and self-disciplined

6. reflective and concerned

7. preoccupied with negative events, feelings of inadequacy and own flaws

This Scale is also five-point, Likert type. Obtained reliability of this scale expressed by Cronbach's alpha coefficient is 0.87 .

Pa Scale (Biro, 1995), or paranoid syndrome scale, assesses sensitivity, hostility and tendency to paranoid interpretation. The reliability of the scale expressed as Cronbach alpha coefficient is 0.88 .

Biographic data were provided by subjects, by choosing from the answers listed on the first page of the battery of questionnaires.

\section{Subjects}

The sample belonged to the convenience type, comprised of 200 subjects, 100 from nonclinical and 100 from clinical adult population. The clinical part of the sample consisted of equal numbers of subjects with depressive and paranoid disorders. Subjects were 
classified in the clinical groups based on the psychiatric diagnosis, established according to the ICD-10 (WHO 1992) criteria. The group of depressive disorders included subjects with dominant depressive symptoms (F32.0, F32.1, F32.2, F32.8, F32.9, F33.0, F33.1, F33.2, F33.4, F33.8, F33.9), excluding bipolar affective disorder, schizoaffective disorder, post-schizophrenic depression, cyclothymia, dysthymia, other and unspecified mood disorders. The group of paranoid disorders included subjects with dominant paranoid symptoms, either paranoid personality disorders or compensated psychotic non-schizophrenic disorders (F22.0 in remission, F23.0 in remission, F 23.3 in remission and F60.0). Patients with the listed diagnoses were treated ambulatory or hospitalised.

Statistical analysis of data was performed using the software SPSS 15.0 (SPSS 2006).

\section{Demographic characteristics of the sample}

The total sample consisted of $38 \%$ men and $62 \%$ women. The distribution by gender was not representative for the population. The average age of subjects was 40 , with standard deviation 10 years; the youngest participant was 19 and the oldest 68 years.

Three groups were statistically significantly different by age, in that the group of patients with depressive disorder was significantly older than non-clinical groups ( $F=7,502 ; D F=2 ; p=.001)$.

Subjects were also significantly different as regards the education level, with those in the clinical part of the sample having significantly lower level of education (Pearson's chi-square=30,959; DF=6; $p=.000$ ).

Non-clinical and clinical groups were statistically different in employment status. The non-clinical group had significantly more employed subjects (Pearson's chi-square=92,425; $D F=8 ; p=.000$ ).

Three groups were statistically different in marital status; the non-clinical group and the group of patients with depressive disorders had more subjects who were married, while patients in the group of paranoid subjects were mostly single (Pearson's chi-square $=33,814$; $D F=6 ; p=, 000)$.

The possible impact of these demographic variables to the value of the dependent variable was checked later through statistical procedures.

\section{Results}

Difference in injunctions between the clinical and nonclinical group

Discriminant analysis determined one significant discriminant function (Table 2). The discriminant function was defined by higher scores on all injunction subscales (Table 3).
As expected, the clinical group had statistically significant higher scores on all injunctions (Tables 4 and 5). Our results are in accordance with TA theoretical assumptions described above, that each form of psychopathology involves the presence of injunctions.

The differences obtained on univariate tests indicated that the nonclinical and clinical group also differ on all injunctions.

Table 2: Parameters of isolated discriminant function

\begin{tabular}{lr}
\hline & Function 1 \\
\hline Charact. Root & $.468(\mathrm{a})$ \\
\% variance & 100.0 \\
Cumulative \% & 100.0 \\
Canonical Correlation & .565 \\
Wilks' Lambda & .681 \\
Chi-square & 73.320 \\
Df & 12 \\
P & $.000 *$ \\
\hline
\end{tabular}

Table 3: Structure matrix of the discriminant function

\begin{tabular}{lr}
\hline & Function 1 \\
\hline Don't exist & $.858^{*}$ \\
\hline Don't think & $.827^{*}$ \\
Don't feel & $.826^{*}$ \\
Don't be important & $.737^{*}$ \\
Don't be well & $.730^{*}$ \\
Don't succeed & $.719^{*}$ \\
Don't be close & $.685^{*}$ \\
Don't belong & $.667^{*}$ \\
Don't grow up & $.575^{*}$ \\
Don't be a child & $.537^{*}$ \\
Don't & $.535^{*}$ \\
Don't be you & $.409^{*}$ \\
\hline
\end{tabular}

Table 4: Group centroids on the discriminant function

\begin{tabular}{lr}
\hline & Function 1 \\
\hline Nonclinical & -.677 \\
Clinical & .684
\end{tabular}




\begin{tabular}{lr|r|r|r|r|r}
\hline & \multicolumn{2}{c}{ Nonclinical } & \multicolumn{2}{c}{ Depressive } & \multicolumn{2}{c}{ Paranoid } \\
\hline & Mean & \multicolumn{1}{c}{ SD } & \multicolumn{1}{c}{ Mean } & \multicolumn{1}{l}{ SD } & Mean & \multicolumn{1}{l}{ SD } \\
\cline { 2 - 8 } Don't exist & 12.38 & 3.336 & 23.16 & 9.244 & 16.80 & 6.643 \\
Don't be you & 5.47 & 2.372 & 7.40 & 2.900 & 6.47 & 2.829 \\
\hline Don't be a child & 2.94 & 1.246 & 5.00 & 2.799 & 3.76 & 2.006 \\
Don't grow up & 10.95 & 3.854 & 14.94 & 5.152 & 13.90 & 4.753 \\
\hline Don't succeed & 8.97 & 3.141 & 13.32 & 5.077 & 12.73 & 4.877 \\
\hline Don't & 13.87 & 4.532 & 18.62 & 5.170 & 16.16 & 4.905 \\
Don't be important & 8.10 & 2.783 & 12.88 & 5.232 & 11.43 & 4.713 \\
\hline Don't belong & 12.85 & 4.914 & 18.64 & 6.433 & 17.47 & 6.526 \\
Don't be close & 7.57 & 3.092 & 12.16 & 4.528 & 10.35 & 4.684 \\
Don't be well & 4.18 & 1.850 & 7.60 & 3.136 & 5.76 & 2.697 \\
Don't think & 13.22 & 4.633 & 21.58 & 7.503 & 18.53 & 6.746 \\
Don't feel & 14.91 & 4.643 & 24.24 & 7.258 & 18.98 & 5.851 \\
\hline
\end{tabular}

Difference in injunctions between depressive and paranoid subjects

A statistically significant discriminant function was isolated for the two clinical groups (Table 6).

The discriminant function was defined by a higher score on the following injunction scales: Don't feel, Don't exist, Don't be well, Don't be a child, Don't, Don't think, and Don't be close (Table 7).

As can be seen in Table 8, the group of subjects with depressive disorders had higher scores on the discriminant function, which means that subjects in this group had overall higher scores on the abovementioned set of injunctions. This finding indicates that depressive subjects reported that they were exposed to various messages that basically communicated that they were not OK, that is, that they should not exist, express their opinions, feelings and needs, be healthy, get close to other people and have initiative, and that they have been receiving these messages more frequently than paranoid subjects. On the other hand, the paranoid group had a lower score on all of these injunctions, which might be due to their minimizing of their own psychopathology. These results will be addressed in more detail in the final discussion section of the results.

Differences between depressive and paranoid subjects on the $L D$ and $P a$ scales

Discriminant analysis was carried out in order to determine the difference between the two clinical groups on the LD and $\mathrm{Pa}$ scales. One statistically significant discriminant function was extracted that was defined by a high score on the LD scale and a somewhat less high score on the $\mathrm{Pa}$ scale (Tables 9 and 10).

The group of depressive subjects had higher scores on the isolated function, which means that depressive subjects had higher scores on both LD and $\mathrm{Pa}$ scales (Table 11).

In the univariate analysis of the equality of arithmetic means of the two groups, one can see that there is no significant difference between depressive and paranoid subjects on the Pa scale (Table 12).

Results indicate that, as was expected, depressive subjects had higher scores on the scale of depression as a trait and showed tendencies that fall within the scope of depressive personality. The finding that may seem unusual at first glance, that depressive subjects also scored higher on the hypersensitivity scale, can be explained by their sensitivity but also their tendency to exaggerate, whereby it is possible that paranoid subjects understated their own psychopathological symptoms, considering that the $\mathrm{Pa}$ scale is a standardised instrument whose discriminating value has been proven multiple times. This finding questions the reliability of the diagnoses in the depressive spectrum, which is much more heterogeneous in comparison with diagnoses from the paranoid spectrum. Depression is often met as a secondary phenomenon in other psychopathological conditions, which is frequently unrecognised in the clinical practice. These assumptions will be considered in more detail in the discussion of the results. 
Table 6: Parameters of the isolated discriminant function

\begin{tabular}{lr}
\hline & Function 1 \\
\hline Charact. Root & $.390(\mathrm{a})$ \\
\% variance & 100.0 \\
Cumulative \% & 100.0 \\
Canonical Correlation & .529 \\
Wilks' Lambda & .720 \\
Chi-square & 29.939 \\
Df & 12 \\
P & $.003 *$ \\
\hline
\end{tabular}

Table 7: Matrix of the isolated discriminant function structure

\begin{tabular}{lr}
\hline & Function 1 \\
\hline Don't feel & .645 \\
Don't exist & .639 \\
Don't be well & .510 \\
Don't be a child & .413 \\
Don't & .394 \\
Don't think & .346 \\
Don't be close & .319 \\
Don't be you & .263 \\
Don't be important & .236 \\
Don't grow up & .170 \\
Don't belong & .146 \\
Don't succeed & .095 \\
\hline
\end{tabular}

Table 8: Group centroids on the discriminant function

\begin{tabular}{lr}
\hline Group & Function 1 \\
\hline Depressive & .612 \\
Paranoid & -.624 \\
\hline
\end{tabular}

Table 9: Parameters of the isolated discriminant function

\begin{tabular}{lr}
\hline & Function 1 \\
\hline Charact. Root & $.212(\mathrm{a})$ \\
\% variance & 100.0 \\
Cumulative \% & 100.0 \\
Canonical Correlation & .418 \\
Wilks' Lambda & .825 \\
Chi-square & 18.481 \\
Df & 2 \\
P & $.000 *$ \\
\hline
\end{tabular}

Table 10: Matrix of the discriminant function structure

\begin{tabular}{lr}
\hline Group & Function 1 \\
\hline Depression - total & .978 \\
$\mathrm{~Pa}-$ total & .384 \\
\hline
\end{tabular}

Table 11: Group centroids on the discriminant function

\begin{tabular}{lr}
\hline Group & Function 1 \\
\hline Depressive & .451 \\
Paranoid & -.461 \\
\hline
\end{tabular}

Table 12: Testing of the equivalence between the group means

\begin{tabular}{lrrrrr}
\hline & $\begin{array}{c}\text { Wilks' } \\
\text { Lambda }\end{array}$ & F & dfl & df2 & p \\
\hline $\begin{array}{l}\text { Pa - total } \\
\begin{array}{l}\text { Depression } \\
- \text { total }\end{array}\end{array}$ & .970 & 3.031 & 1 & 97 & .085 \\
\hline
\end{tabular}

Table 13: Canonical correlation between the LD and Pa scores and injunctions and significance of canonical correlations

\begin{tabular}{llrrrr}
\hline & $\begin{array}{l}\text { Canonical } \\
\text { correlation }\end{array}$ & \multicolumn{1}{c}{$\begin{array}{l}\text { Wilks' } \\
\text { Lambda }\end{array}$} & Chi-square & \multicolumn{1}{c}{ DF } & P \\
\hline 1 & .842 & .248 & 265.782 & 24.000 & .000 \\
2 & .387 & .850 & 30.880 & 11.000 & .001 \\
\hline
\end{tabular}


Table 14: Canonical loadings for the LD and Pa set

\begin{tabular}{lll}
\hline & $\mathbf{1}$ & $\mathbf{2}$ \\
\hline $\mathrm{Pa}-$ total & -.877 & -.480 \\
$\mathrm{D}-$ total & -.931 & .365 \\
\hline
\end{tabular}

Table 15: Canonical loadings for the injunctions set

\begin{tabular}{llll}
\hline & \multicolumn{1}{l}{$\mathbf{1}$} & \multicolumn{1}{l}{$\mathbf{2}$} \\
\hline Don't exist & -.895 & -.162 \\
\hline Don't be you & -.633 & .001 \\
\hline Don't be a child & -.759 & -.230 \\
\hline Don't grow up & -.465 & .060 \\
\hline Don't succeed & -.716 & .124 \\
\hline Don't & -.557 & .397 \\
\hline Don't be important & -.722 & -.095 \\
\hline Don't belong & -.687 & -.487 \\
\hline Don't be close & -.722 & -.291 \\
\hline Don't be well & -.800 & -.231 \\
\hline Don't think & -.852 & .266 \\
\hline Don't feel & -.894 & -.038 \\
\hline
\end{tabular}

in a positive direction, so we termed this dimension don't and Belong (Table 15). This structure of injunctions is more common in depressive than in paranoid disorders (Stewart \& Joines, 1996). The first canonical function explained $54.2 \%$ and the second only $5.9 \%$ of the variance.

There is significant association between the absence of depressive and paranoid symptoms and the absence of injunctions, which is in line with the theoretical expectations within TA theory. In addition, also in accordance with the TA theory, the results show that the higher the proneness of a person to manifest depressive personality traits, the higher is the probability of having the injunction Don't, and not having the injunction Don't belong. These findings could corroborate Beck at al's (1983) theory of dysfunctional cognitive schema, i.e. of sociotropy as a personality dimension. Sociotropic personalities, which can be found as one of the subgroups of depressive population, show orientation to people; in particular they show a pronounced need to be accepted and intimate, and when they lose it they become depressed.

The first canonical dimension explained $38.4 \%$ and the second only $0.9 \%$ of the variance of the second set. The first canonical dimension of the second set explained $58 \%$ and the second one only $2.7 \%$ of the variance of the first set.
Correlation between injunctions and the $L D$ and $\mathrm{Pa}$ scores

In order to clarify the results obtained (for the clinical groups), we decided to perform the canonical correlation analysis of the linkage of injunctions with the height of the score on LD and Pa scales, in order to see the character of the differences between the two clinical groups when the differentiation criterion is not psychiatric diagnosis but rather an objectivised approach of classifying subjects into these two groups of psychopathological disorders. Two statistically significant correlations were found (Table 13).

The first canonical function, within the first set of variables, was characterised by low scores on both the LD and $\mathrm{Pa}$ scale (Table 14). The second canonical function was characterised by low scores on the $\mathrm{Pa}$ scale and higher score on the LD scale. We termed the first canonical function absence of depressive and paranoid characteristics and the second one depressive characteristics. The first canonical function of the first set explained $81.8 \%$ of variance and the second $18.2 \%$ of variance of the first set.

In the second set of variables, the first canonical function was characterised by low score on all injunctions, so we termed it absence of injunctions. The second canonical function was defined by the injunction don't belong in a negative direction and don't.

Effects of demographic and control variables on injunctions

We found a statistically significant effect ( $F=1.304$, $p=.011, d f=2)$ of the variable educational level $(F=3.424$, $p=.004, d f=6)$ and a combined effect of the variables group, sex and employment status $(F=2.128, p=.019$, $\mathrm{df}=12$ ). It was expected that belonging to one of the groups (nonclinical, depressive or paranoid) would have a statistically significant effect on injunctions. The clinical group had a higher average score on all injunctions. As regards educational level, subjects with only elementary school education had the highest average score on all injunctions. Retired and unemployed subjects from the depressive group, male and female almost equally, had the highest average score on most injunctions.

We can assume that the significant effect of the variable educational level found in the study was because the clinical groups comprised considerably more subjects with lower educational level due to decreased professional functioning, and that this result is not a real effect of the variable educational level on injunctions. The combined effect of the three above mentioned variables was expected in light of our findings that patients with depressive disorder have highest scores on injunctions, similarly distributed male and female, who also most frequently had impaired professional functioning. 


\section{Discussion}

Subjects with depressive and paranoid symptoms scored significantly higher on almost all injunctions, which is in line with the theoretical assumptions of TA. We have already mentioned that Berne (1972) emphasised that injunctions lead to chronic dysfunction in vital areas of life, which is certainly commonly seen in persons with mental illnesses. According to the World Health Organisation (1992) recommendations for classification of mental disorders, adequate functioning in vital areas of life is indeed one of the major criteria for differentiating psychopathology and mental health. Our results show that the concept of injunctions can differentiate between persons with and without mental disorders.

The difference found between depressive and paranoid subjects in injunctions suggests that depressive subjects were exposed to more destructive messages than paranoid subjects, in both content and frequency. This may be a result of the tendency of depressive subjects to overestimate and paranoid subjects to underestimate their own mental problems. It is also possible that the described differences result from the fact that persons with depressive traits are aware of their script pathology, unlike paranoid subjects who might deny it. These assumptions need to become the topic of future research.

The Pa scale score which we found to be higher in subjects with depressive disorders than in subjects with paranoid disorders is rather confounding. It seems that the shortcomings of self-report techniques in clinical research have become most apparent here; unless we exclude the possibility that depressive subjects are more sensitive than paranoid subjects, which is in our opinion highly improbable. It seems more likely that subjects with depressive disorders overestimated whereas subjects with paranoid disorders underestimated their mental problems. These results have shown that depressive persons tend to see themselves as victims of mistakes made by others, which is probably not that unexpected.

The results of the canonical correlation analysis of injunctions and scores on LD and $\mathrm{Pa}$ scales indicate statistically significant correlation between the absence of depressive and paranoid disturbances and the absence of injunctions, as well as between depressive characteristics and the dimension defined by the injunction Don't (positive correlation) and Don't belong (negative correlation). These findings are clearly in line with our theoretical assumptions, although they still do not clarify the structure of injunctions in paranoid subjects. Further studies in this area would help clarify the inconsistencies surrounding the potential of the concept of injunctions to differentiate between persons with various disorders, in this case depressive and paranoid.
As regards self-report techniques used in our study, the situation may be additionally complicated by the problems related to comprehension of the verbal content in the clinical population, considering the significantly lower educational level in the clinical part of the study sample. In order to overcome the shortcomings of possible incomprehension of the verbal content in the clinical population, we propose that clinical observation and/or structured clinical interviews should be used complementary to the questionnaire technique, as this should improve validity of data.

Furthermore, in order to overcome possible limitations of applied instruments, it is important that they are uniform in that they measure subject's personality traits and current psychological state. If possible, the socalled trait and state scales should be used, in order to improve the objectified assessment of the type of psychopathological disorder. In addition, controlling scales would considerably alleviate the problem of conscious and unconscious censorship of responses in the applied questionnaires. It is a longer and more expensive way to improve research instruments; however, it would undoubtedly improve the validity of research data.

So far we can only assume which factor or combination of factors has/have contributed to the confounding results. We are more certain that these factors pertain to methodological limitations of our study, or clinical research in general. In order to clarify potential reasons for this, it is important to tackle the issue of the validity of psychiatric diagnosis. As has already been said, diagnoses for the group of depressive disorders are much more heterogeneous than those from paranoid disorders, since depression is seen as a secondary phenomenon in most psychopathological categories. To improve the reliability of psychiatric diagnosis, we believe it would be useful to introduce diagnosis from both first and second axis according to the DSM-IV (APA 2000) criteria, in order to avoid overlapping of states and traits, i.e. to separate these two aspects of psychological functioning, to know which phenomenon belongs to which aspect. Of course, we do not claim that this will always be possible. It would be useful also to apply some of the 'objectified' instruments for assessing the type of psycho-pathological disorder, such as standardised symptom check lists. Finally, we should not overlook the possibility of comorbidity of the two studied syndromes, despite the attempts at precise psychiatric diagnosis, which, even when very mildly expressed, can obscure the character of the differences between these two clinical groups.

It is worth to mentioning the demographic differences between the clinical and nonclinical part of the sample. These differences were expected and unavoidable and should be kept in mind when designing a study and especially statistical analysis. Although in our study 
they did not prove to have a crucial effect on dependent variables, they should be controlled in order for research to have methodological validity. Otherwise, the sample should be equable following the demographic variables, which is a rather uneconomical way in clinical research in every respect except strictly methodological.

\section{Conclusion}

We can conclude that the hypotheses which the study aimed to test got partly expected confirmation. The clinical group scored significantly higher on all injunctions. Compared with paranoid subjects, depressive subjects were more likely to have the following injunctions: Don't feel, Don't exist, Don't be well, Don't be a child, Don't, Don't think, and Don't be close. Depressive characteristics were associated with Don't and the absence of Don't belong.

\section{Author affiliations}

Danijela Budiša: Centre for extended treatment of drug addicts, Clinic for Treatment of Drug Addiction, Institute of Psychiatry, Clinical Centre of Vojvodina

Vesna Gavrilov-Jerković: Psychology Department, Faculty of Philosophy, Novi Sad

Aleksandra Dickov, Nikola Vučković \& Sladjana Martinovic Mitrovic: Clinic for Treatment of Drug Addiction, Institute of Psychiatry, Clinical Centre of Vojvodina

$\begin{aligned} & \text { Danijela Budiša can be contacted at } \\ & \text { danijela1@neobee.net }\end{aligned}$

\section{References}

Akiskal, H.S. \& Cassano, G.B. (1997). Dystimia and the spectrum of chronic depressions. New York: Guilford Press.

American Psychiatric Association (2000) Diagnostic and Statistical Manual of Mental Disorders, Fourth Edition, Text revision, Washington DC: American Psychiatric Association

Beck, A. T., Rush, A. J., Shaw, B. F. \& Emery, G. (1979) Cognitive therapy of depression. New York: Guilford.

Beck, A. T., Epstein, N., \& Harrison, R. (1983). Cognitions, attitudes and personality dimensions in depression. British Journal of Cognitive Psychotherapy, 1, 1-16.

Berne, Eric (1972). What do you say after you say hallo? Psychology of human destiny. New York: Grove Press

Biro, M. (1995). Dijagnostička procena ličnosti MMPI-202. Novi Sad: Futura publikacije, Filozofski fakultet.

Björk, A. (1997). The Script concept in Transactional Analysis from a Family therapy perspective. Unit for Postgraduate Psychotherapy Training and Education, Lund University.

Drego, P. (1994). Happy Family - Parenting through Family

Rituals. Bombay: Vision Wordtronic Ltd.
Ernst, $F$ (1971). The OK corral: the grid for get on with. Transactional Analysis Journal, 1, 33-42.

Erskine R., Zalcmann, M. (1979). The racket system. Transactional Analysis Journal, 9, 51-59.

Gavrilov-Jerković, V., Budiša, D., Lekić-Babić, N., \& Čolović, P. (2010). Procena skriptnih zabrana (SSZ-skala). U:Biro, M., Smederevac, S., Novović (ur.) Procena psiholoških i psihopatoloških fenomena, CPP, Beograd, 123-140.

Goulding, R \& Goulding, M (1976) Injunctions, decisions and redecisions Transactional Analysis Journal, 6:1, 41-48

Goulding, Robert L. \& Mary M. (1978) The Power is in the Patient San Francisco: TA Press

Goulding, M. \& Goulding, R. (1979). Changing lives through redecision therapy. New York: Grove press.

Hartman, C \& Narboe, N (1974) Catastrophic Injunctions Transactional Analysis Journal 4: 2 10-12

Holloway, W.H. (1977). Transactional analysis: An integrative view. In Barnes, G., (ed.) Transactional Analysis After Eric Berne. London: Harper \& Row.

Johnsson, R. (2011). Client Assessment in Transactional Analysis - A Study of the Reliability and Validity of the Ohlsson, Björk and Johnsson Script Questionnaire. International Journal for Transactional Analysis Research, 2, 19-33.

Joines, V. \& Stewart, I. (2002). Personality adaptations. Chapel Hill: Lifespace publishing.

Kahler, Taibi (1975) Drivers: The Key to the Process of Scripts Transactional Analysis Journal 5:3 280-284

Lammers, W.(1994). Injunctions as an impartment to healthy egostate functioning. Transactional analysis Journal, 24, 250-265.

McNeel, J The Parent Interview Transactional Analysis Journal, 1976, 6(1), 61-68

Novović, Z., Nedimović, T., \& Biro, M. (2007). Stanje depresivnosti: sindrom ili raspoloženje? Psihologija, 40, 447-461.

Scilligo, P., D'Aversa, C., Liverano, A., Schietroma S, \& Guglielmotti, F. (1999). II questionario ESPERO: la misurazione delle ingiunzioni e delle controingiunzioni. Psicologia Psicoterapia e Salute, 5, 137-166.

Schneider, K. (1958). Psychopatic personalities. Psychology, 62 $1181-1196$

SPSS (2006) SPSS 15.00 Chicago: SPSS Inc Downloaded 1 September 2011 via http://en/softonic.com

Steiner, C. (1967). A script checklist. Transactional Analysis Bulletin, 6, 38-40.

Steiner, C. (1974). Scripts people live. Transactional analysis of life scripts. New York: Grove press.

Stewart, I. \& Joines, W. (1996). TA Today: A new introduction to Transactional analysis. Nottingham: Russell Press Ltd.

World Health Organisation (1992). Svetska zdravstvena organizacija ICD-10 Klasifikacija mentalnih poremećaja i poremećaja ponašanja: Klinički opisi i dijagnostička uputstva. Beograd: Zavod za izdavanje udžbenika. 